\title{
Self-perceived employability among undergraduate students at a South African university
}

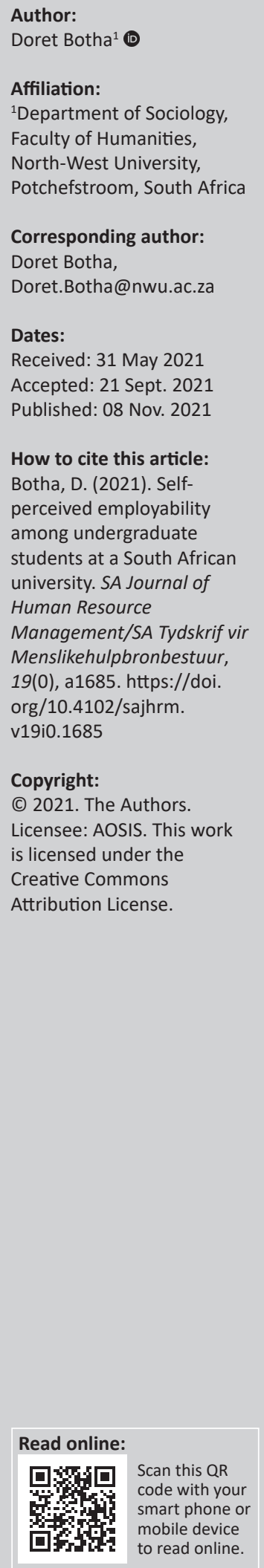

Orientation: South Africa has been suffering from persistently high levels of unemployment since 2008. The youth is regarded as the most at-risk group in the South African labour market and unemployment amongst the youth is considered one of the most critical socio-economic problems in South Africa. Increasing one's employability is essential to securing employment and enhancing one's well-being.

Research purpose: This study aimed to explore the self-perceived employability of undergraduate students at a South African university.

Motivation for the study: Currently, there is a scarcity of published research on the selfperceived employability amongst undergraduate students at higher education institutions in South Africa.

Research approach/design and method: The study was conducted within a positivistic research paradigm. A quantitative-based cross-sectional survey design was used. Convenience sampling was used to select the students who were included in the survey. Data were collected through a web-based survey, using a standardised coded questionnaire that consisted of a five-point Likert-type scale.

Main findings: The results indicated that the respondents were relatively confident about their internal employability, but they were less confident about their opportunities in the external labour market.

Practical/managerial implications: Understanding one's employability and the accompanied issues creates awareness of one's potential, skills and knowledge to become a successful citizen and employee.

Contribution/value-add: The study shed light on the self-perceived employability of undergraduate students at a South African university and consequently contributes to the existing literature on employability in the South African context.

Keywords: external employability; higher education; internal employability; self-perceived employability; undergraduate students.

\section{Introduction}

From 1998 to 2008, the South African economy grew at an average rate of 4\% per annum; however, this 11-year growth period ended with the 2008 global recession (Yu \& Swanepoel, 2021). Since then, the country's economy has been 'going downhill' (Wakefield, Yu, \& Swanepoel, 2020, p. 1) and the country has suffered from 'persistently high levels and rates of unemployment' (Yu \& Swanepoel, 2021). The poor economy and unemployment rates in the country were further exacerbated by the global Covid-19 pandemic (Reuters, 2021). In the second quarter of 2021, the country recorded its highest unemployment rate (34.4\%) (Statistics South Africa, 2021b, p. 7) since the start of the Quarterly Labour Force Survey in 2008 (Statistics South Africa, 2021a). If those who are discouraged from seeking work are included (i.e. the expanded definition of unemployment), the figure rose to $44.4 \%$ (Statistics South Africa, 2021b, p. 8). The youth is regarded as the most at-risk group in the South African labour market and the unemployment rate was estimated at $64.4 \%$ for those aged between 15 and 24 years and $42.9 \%$ for those aged between 25 and 34 years (Statistics South Africa, 2021b, p. 15). The graduate unemployment rate was estimated at $11 \%$ (Statistics South Africa, 2021b, p. 14).

The continued high youth unemployment rate is considered as one of the most critical socioeconomic problems in South Africa (Statistics South Africa, 2020). Youth unemployment is regarded as a potential threat to social stability (Jordan, 1982, as cited in Edgell \& Granter, 2019, 
p. 240). Furthermore, it is associated with property crimes such as burglary and theft (Hakim, as cited in Edgell \& Granter, 2019, p. 239). Long-term youth unemployment may have negative economic and health consequences (Edgell \& Granter, 2019, p. 237). Young people's transition to adulthood status is delayed, as they remain dependent upon their families for economic and social support. Furthermore, long periods of unemployment for young people may result in permanent personal scars and may influence one's happiness, job satisfaction and health for many years later (Edgell \& Granter, 2019, p. 237).

Unemployment in South Africa has a structural nature, thereby indicating 'an inability of an economy to provide employment for the total (or potential) labour force, even at the peak of its economic cycle' (Cloete, 2015, p. 515). Furthermore, it points to a mismatch between the type of skills supplied and demanded in the labour market (Wakefield et al., 2020, p. 2). Young people seeking employment in the labour market are often not well educated and do not possess the necessary skills and work experience demanded by employers in the labour market (Statistics South Africa, 2020). Globally, education is considered a key instrument to developing one's human capital and consequently one's employment prospects. The more educated people are, the more likely their chances are to secure employment and jobs with good working conditions (Statistics South Africa, 2020). This is also confirmed by human capital theory, which suggests that investment in training and education would increase internal mobility and decrease external mobility. Increasing one's human capital assists in making individuals more employable and consequently increases internal mobility (Groot \& Van den Brink, 2000, p. 573).

Although qualifications alone cannot guarantee future employment, they contribute to one's employability (Tymon, 2013, as cited in Harry, Chinyamurindi, \& Mjoli, 2018, p. 2). Employability concerns 'work and the ability to be employed' (Hillage \& Pollard, 1998, p. 3). It encompasses the 'ability of the individual to gain initial employment, to maintain employment and to obtain new employment if required' (Hillage \& Pollard, 1998, p. 3). It also, ideally, includes the quality of employment; some individuals may be able to obtain employment, but it may be 'below their level of skills or in low paid, undesirable or unsustainable jobs' (Hillage \& Pollard, 1998, p. 3). Today, employers want to recruit individuals who possess specific knowledge and skills related to the type of work to be completed and who have basic employability skills (such as communicating clearly, thinking critically and innovatively and solving complex problems) to contribute to the organisation's success (Quiring, Boys, \& Harris, 2017, p. 537). Therefore, employability is of utmost importance for graduates (Moolman, 2017, p. 26). Understanding one's employability and the accompanied issues creates awareness of one's potential, skills, knowledge and prospects to become a successful citizen and employee (Hooley, 2017).

\section{Research purpose and objectives}

The purpose and main objective of this study were to explore the self-perceived employability of undergraduate students at a South African university. The secondary objectives were to determine whether selected socio-demographic variables (gender, year of study, faculty of study, geographical location in which respondents mainly grew up and previous and current work experience) influence the self-perceived employability of undergraduate students.

The article begins with a conceptualisation of self-perceived employability, followed by a discussion of the main theoretical perspectives on employability. Next, the association between selected socio-demographic variables and self-perceived employability is discussed. Thereafter, the research methodology used for the study is outlined, followed by a discussion of the empirical results. The article concludes with recommendations to the research community and to the university under investigation pertaining to the findings of the research.

\section{Literature review Defining and conceptualising employability}

There is an abundance of definitions of employability reflected in the literature, highlighting different characteristics of (prospective) employees, for example, 'physical and cognitive suitability, learning, flexibility, adaptation and mobility', amongst others; however, all have in common the notion of 'employment as an outcome' (Thijssen, Van der Heijden, \& Rocco, 2008, p. 167). According to Rothwell (2015, p. 338), the definition provided by Hillage and Pollard (1998) is the most widely cited and comprehensive definition in the literature. Hillage and Pollard (1998, p. 3) stated that 'employability is about the capability to move self-sufficiently within the labour market to realise potential through sustainable employment'. For the individual, employability depends on the following three factors: firstly, one's knowledge, skills and attitudes; secondly, the way one uses those assets and presents them to employers and thirdly, the context (such as individual circumstances, e.g. family and domestic responsibilities, disabilities and household conditions and the status of the labour market, e.g. the demand and supply of labour, job openings and employer recruitment and selection behaviour) within which one seeks work (Hillage \& Pollard, 1998, pp. 3-4). Hillage and Pollard (1998, p. 3) further asserted that an individual's 'employability assets' consist of baseline assets (i.e. the basic skills and crucial individual attributes, e.g. reliability and integrity), intermediate assets (i.e. occupation-specific and key skills, e.g. communication and problem solving and key individual attributes, e.g. motivation and initiative) and high-level assets (i.e. skills that assist in contributing to organisational performance, e.g. teamwork and selfmanagement/regulation).

A distinction is made between one's internal and external employability. Internal employability reveals the worth of an 
employee's human capital in the internal labour market. It refers to an employee's capability and willingness to remain employed with his or her present employer (Juhdi, Pa'Wan, Othman, \& Moksin, 2010, p. 2). In relation to students, internal determinants of employability include, amongst other features, ambition, self-confidence and academic performance, which play a vital role in securing employment (Paterson, 2017, p. 248). External employability reveals the value of workers' human capital in the external labour market. It refers to the ability and willingness of an employee to switch to a similar or another job in another firm (Juhdi et al., 2010, p. 2). In relation to university students, external determinants include, amongst other features, 'university reputation, the field of study credibility and demand for the field of study' (Paterson, 2017, p. 248).

\section{Theoretical approaches to employability}

According to Rothwell (2015), there are four main approaches to employability, namely employability in public policy, employability in education, employability in human resource management (an organisational perspective) and employability as perceived by the individual. The first approach, employability in public policy, developed because of fears about rising unemployment in the Western world since the 1990s. As a result, international organisations (e.g. the European Union, the United Nations and the Organisation for Economic Co-operation and Development) and government departments requested reports that should entail information regarding the status of the labour market and recommendations on how public policy might respond to changing circumstances and how skills could be developed in the labour market (Rothwell, 2015, p. 339). The focus was on reducing unemployment and the accompanied social consequences (Vargas, Sanchez-Queija, Rothwell, \& Parra, 2018, p. 227).

The educational approach focuses on graduates' access to and suitability for the labour market in often difficult economic circumstances. Emphasis is placed in curriculums on enhancing undergraduates' employability skills, which also include soft skills sought by employers (Rothwell, 2015, p. 339). In this regard, different models were developed, such as the following:

- The Decision, Opportunity awareness, Transition learning and Self-awareness (DOTS) model developed by Bill Law and Tony Watts of the National Institute for Careers Education and Counselling, Cambridge: This model focuses on career education and planning, which according to the developers, encompass four steps: decision learning, opportunity awareness, transition learning and self-awareness (Law \& Watts, 2003, p. 1).

- The Understanding, Skills, Efficacy and Metacognition (USEM) model developed by Peter Knight and Mantz Yorke: This model describes the following graduate attributes: understanding, skills (subject-specific and generic social practices), efficacy beliefs and metacognition (reflection or strategic thinking), which may increase one's employability (Knight \& Yorke, 2003, p. 8).
- The CareerEDGE model developed by Lorraine Dacre Pool and Peter Sewell: This model describes five components that may enhance students' employability, namely career development learning, experience (work and life), degree subject knowledge (understanding and skills), generic skills and emotional intelligence (Dacre Pool \& Sewell, 2007, p. 281).

The organisational or human resource management approach focuses on employer-led employability strategies to assist individuals to 'fit into changing job roles' (Rothwell, 2015, p. 342) and to 'sustain their careers in the light of increased job instability and insecurity' (Vargas et al., 2018, p. 227). It furthermore aims at 'optimising the deployment of staff in order to increase the organisation's flexibility and competitive advantage' (Nauta et al., 2009, as cited in De Vos, De Hauw, \& Van der Heijden, 2011, p. 439).

The individual approach to employability focuses on the individual's own ability and capability to find and keep a job of an appropriate level (Vargas et al., 2018, p. 227). This includes the individual's understanding of how well he or she is likely to perform in securing employment (Rothwell, 2015, p. 343). The individual approach to employability includes three main approaches, namely competence-based employability, trait-based (dispositional) employability and self-perceived employability (Vargas et al., 2018, p. 227). The competence-based employability approach focuses on an individual's knowledge, skills and abilities that will result in effective performance in the internal and external labour market (De Vos et al., 2011, p. 439). The trait-based (dispositional) employability approach refers to the proactive attitudes adopted by individuals to create and realise opportunities in the labour market (Fugate \& Kinicki, 2008, p. 505). The self-perceived employability approach focuses on individuals' perceptions of their own abilities, capabilities and skills (internal dimensions) and their perceptions of the influence of the external labour market and the importance of their qualifications or professions (external dimensions) when trying to secure a job (Vargas et al., 2018, p. 227). Therefore, the approach not only focuses on internal and external dimensions of employability but also their interactions with one another, in other words how the perception of one's own capacities and skills (internal dimensions) influences the perceptions of the external labour market (external dimensions) and how the perception of the external labour market (external dimensions) influences the perception of one's own capabilities (internal dimensions) (Batistic \& Tymon, 2017, as cited in Vargas et al., 2018, p. 4).

In terms of the self-perceived employability approach, Rothwell, Herbert and Rothwell (2008) developed a theoretical model (see Figure 1) to measure self-perceived employability amongst undergraduate university students. The model comprises four components, namely perceptions of students' self-belief in terms of skills and abilities, perceptions of the reputation of the university attended, perceptions of the status and credibility of students' chosen 


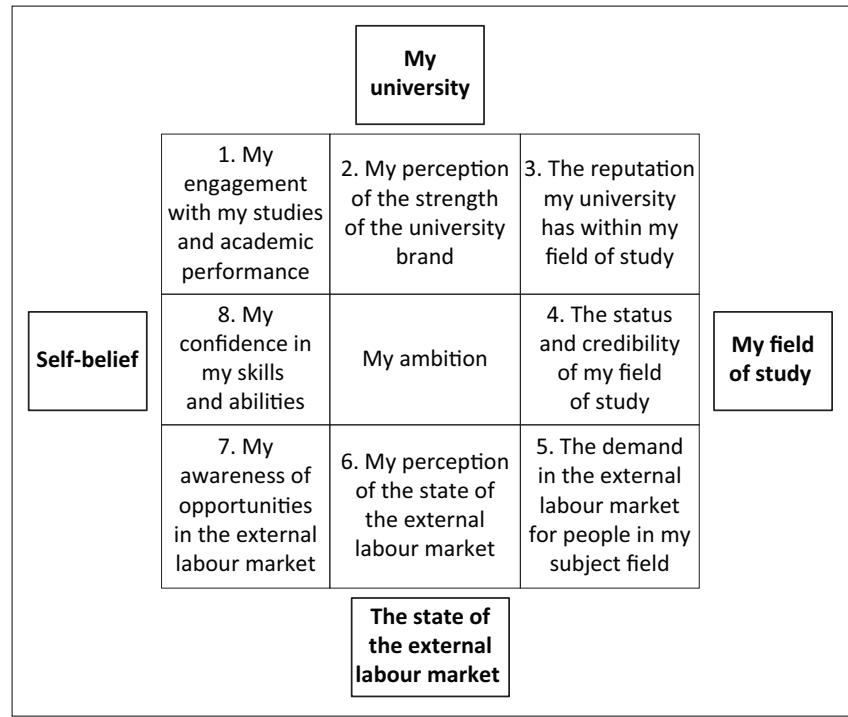

Source: Rothwell, A., Herbert, I., \& Rothwell, F. (2008). Self-perceived employability: Construction and initial validation of a scale for university students. Journal of Vocational Behavior, 73(1), 1-12. https://doi.org/10.1016/j.jvb.2007.12.001

FIGURE 1: Students' self-perceived employability.

field of study and perceptions of the state of and opportunities in the external labour market (Rothwell et al., 2008, p. 3).

Self-belief (also referred to as self-efficacy) is regarded as the belief a person has in his or her ability to successfully accomplish or realise goals (Quiring et al., 2017, p. 537). Selfbelief represents an internal dimension of employability (Rothwell et al., 2008, p. 2; Vargas et al., 2018, p. 228). Self-belief about one's vocational or job-related knowledge and skills and the ability to conduct an efficient, successful job search might influence individuals' self-perceptions of employability (Rothwell et al., 2008, p. 2). The current state of the external labour market and job opportunities available in the labour market might also influence one's perceptions of employability (Rothwell et al., 2008, p. 2). Employment opportunities for graduates of tertiary education are closely related to the economic development of the country and its ability to create employment opportunities in the labour market (Stojanováa \& Blaškováa, 2014, p. 641). It is believed that the reputation of the university attended lends credibility to the job-seeking potential of individuals and therefore might influence selfperceptions of employability (Murray \& Robinson, 2001, as cited in Rothwell et al., 2008, p. 2). Applicants from universities with higher reputational capital are more likely to receive positive responses compared with applicants showing credentials from universities with lower reputational capital (Nogales, Córdova, \& Urquidi, 2020, p. 538; Qenani, MacDougall, \& Sexton, 2014, p. 210). It is furthermore believed that there is higher demand for individuals with degrees in particular fields of study, and this might also influence one's self-perceptions of employability (Rothwell et al., 2008, p. 2). The choice of field of the study might limit employment outcomes (Stojanováa \& Blaškováa, 2014, p. 641). Rothwell et al. (2008, p. 4) developed a 16-item questionnaire based on the theoretical model to measure undergraduate students' selfperceived employability. The validity and reliability of the instrument is further elaborated on under the Research design and methodology section.

\section{Socio-demographic variables and self-perceived employability}

According to Rothwell and Arnold (2007, p. 26), there is an interest in the associations between demographic measures and self-perceived employability. For this particular study, the influence of the following socio-demographic variables on the self-perceived employability of university students was measured and discussed: gender, year of study, faculty of study, geographical location in which respondents mainly grew up and previous and current work experience.

Previous research shows mixed results for gender in terms of self-perceived employability. In a study conducted by Vargas et al. (2018, p. 233), which measured self-perceived employability amongst undergraduate students at universities in Spain, gender differences were reported, and the mean scores obtained by men were higher than the scores obtained by women. Similar results were found by Qenani et al. (2014, p. 210), whose study measured employability perceptions amongst students of California Polytechnic State University in the USA, which found that women were less confident about their employability skill sets than men. The results were also confirmed by a study conducted by Räty et al. (2020, p. 9), which measured the perceived employability amongst Finnish university students. The results revealed that women perceived their employability less positively than did men. In contradiction to these results, a study conducted by Rothwell, Jewell and Hardie (2009, p. 158), measuring the self-perceived employability amongst postgraduate students of a university's business school in the Midlands region of the United Kingdom, revealed no significant difference in the mean scores of men and women. Similar results were obtained in a study conducted by Karli (2016, p. 857), measuring the self-perceived employability amongst university students and graduates of a sports department of Abant Izzet Baysal University in Turkey; no significant differences were found between the scores of the different genders.

Previous research revealed self-perceived employability differences in terms of field of study. In the study conducted by Vargas et al. (2018, p. 233), students studying degrees in arts and humanities scored lower on self-perceived employability than those studying degrees in other fields of study. This was followed by students studying degrees in social sciences, legal studies and sciences. The highest mean scores were obtained for students studying degrees in engineering and architecture and health sciences. The study conducted by Räty et al. (2020, p. 9) revealed that students studying medicine and computing science showed a significantly higher level of self-perceived employability than all other groups. Students studying humanities displayed the lowest self-perceived employability, followed by students studying nursing sciences, forest sciences and biology. Students studying social sciences, business studies and law displayed medium levels of self-perceived employability.

Employability can be affected by experience (in work and in life) (Dacre Pool \& Sewell, 2007, p. 284). Graduates who have 
previous work experience are more likely to secure employment than graduates without such experience (The Pedagogy for Employability Group, 2004, as cited in Dacre Pool \& Sewell, 2007, p. 284). In general, employers prefer to hire people who have work experience (Knight \& Yorke, 2003, p. 4). Helyer and Lee (2014) examined the role of work experience in the future employability of graduates in higher education. The study demonstrated that subject knowledge in combination with real-life workplace experience (e.g. via an internship) provides 'a catalyst for future innovation, development and success' (Helyer \& Lee, 2014, p. 368). Qenani et al. (2014, p. 208) found a significant relationship between work experience gained during academic studies and employability perceptions, where perceptions of employability increased when respondents reported work experience gained through an internship. The study conducted by Karli (2016, p. 857) revealed that respondents who had work experience in their study field reported higher employability perceptions than their inexperienced counterparts. These results were also confirmed by Räty et al. (2020, p. 9), who found that students 'having had at least half a year of work experience showed higher employability optimism than those who had less working experience or no experience at all'. Jackson and Wilton (2017, p. 757) conducted research amongst business undergraduates from vocationally focused universities based in the United Kingdom and Australia and found a positive relationship between work-integrated learning and selfperceived employability, emphasising the importance of parttime work during one's studies.

Previous research reported age differences with regard to self-perceived employability. Van der Heijden (2002, p. 49) compared employability perceptions amongst three age groups of the working population: the starters (20-34 years), the middle-aged (35-49 years) and the seniors (50+). The results indicated that the older the employee, the lower his or her employability perceptions (Van der Heijden, 2002, p. 53). Rothwell et al.'s (2008, p. 9) study conducted amongst business bachelor degree students in three United Kingdom universities revealed older students having lower levels of self-perceived employability. Karli (2016, p. 857) found significant differences between the mean scores of senior students and newly graduated students, where senior students scored significantly higher on self-perceived employability compared with newly graduate students. The author ascribed this tendency to graduates' failure and unsatisfied expectations in the labour market. Qenani et al. (2014, p. 208) found a negative relationship between perceived employability and length of time at university; the senior students displayed lower perceptions of employability than second-year students. Jackson and Wilton (2017, p. 757) found lower levels of perceived employability amongst finalyear students. According to these authors, students become less confident when they become aware of the opportunities and realities of the labour market.

According to Watson (2017, p. 277), 'people do not enter the occupational structure with equal opportunities'. People's class, family and educational background influence the resources they take into the labour market and their aspirations. Parents' occupational and class background may have a significant effect on an individual's life chances. Harry et al. (2018, p. 5) investigated the factors that affect employability amongst final-year students at a rural university in South Africa. As the university was situated in a rural area, a large number of the students who took part in the research came from a low socio-economic background. The findings revealed that background is a significant factor when choices are made with regard to education and career paths. The findings further showed that the higher education institution attended is a key factor in determining how an individual is perceived in the South African labour market. Van Broekhuizen (2016) investigated the association between higher education institutions and graduate employment and unemployment probabilities in South Africa. The findings revealed that graduates who attended traditional universities were found to be less likely unemployed than graduates who attended comprehensive universities (Van Broekhuizen, 2016, p. 21). Traditional universities refer to the general academic universities that offer mainly theoretically oriented diplomas and degrees. Universities of technology resemble the former technikons and mainly offer vocational diplomas and degrees. Comprehensive universities refer to institutions that offer a combination of these types of qualifications (Van Broekhuizen, 2016, p. 10). The finding was also confirmed by Oluwajodu, Blaauw, Greyling and Kleynhans (2015, p. 7), who examined the perceived causes of graduate unemployment in the South African banking sector. The results suggested that the kind of institution that a graduate attends and the perception of employers about those institutions may affect one's chances to secure employment.

This section conceptualised employability, discussed the theoretical perspectives of employability, elaborated on the theoretical model developed by Rothwell et al. (2008) to measure the self-perceived employability amongst undergraduate university students and discussed the sociodemographic variables that might influence self-perceptions of employability. The following section presents and discusses the empirical results of the study.

\section{Research design and methodology}

The study was conducted within a positivistic research paradigm. The ontological and epistemological philosophical positions of objectivism and empiricism informed the study. A quantitative-based cross-sectional survey design was used (see Creswell \& Creswell, 2018, p. 149); the data were collected at one point in time.

\section{Research setting, population and sampling}

The survey was conducted amongst undergraduate students who studied full-time at a South African university. Convenience sampling was used to select the students who were included in the survey. Convenience sampling is 
adopted as a method by researchers to obtain data from a group of people or units that are conveniently available (Zikmund, Babin, Carr, \& Griffin, 2010, p. 396). In total, 241 undergraduate students participated in the research.

\section{Instrumentation and data collection}

Data were collected through a web-based survey (QuesionPro), using a coded questionnaire. The questionnaire included two sections. Section A contained biographical questions, which included items on gender, year of study, faculty of study, geographical location in which respondents mainly grew up and previous/current work experience. For Section B, the 16-item self-perceived employability scale for university students developed by Rothwell et al. (2008) was used. The scale used a five-point Likert-type scale ranging from strongly disagree (1) to strongly agree (5). The measurement instrument was tested amongst business bachelor degree students at three universities in the United Kingdom. The Cronbach's alpha coefficient for the overall 16-item scale yielded a value of 0.75 and showed high reliability and internal consistency (Rothwell et al., 2008, p. 7). The scale's factor structure also confirmed external $(\alpha=0.76)$ and internal $(\alpha=0.66)$ dimensions of employability (Rothwell et al., 2008, p. 7). External dimensions included respondents' perceptions of the state of the external labour market, the strength of the university's brand and the status and credibility of their field of study. Internal dimensions included respondents' perceptions of self-belief (i.e. their confidence in their skills and abilities) (Vargas et al., 2018, p. 229). The wording of some of the items was slightly adapted to enhance understanding of the individual items. Furthermore, the item 'The skills and abilities that I possess are what employers are looking for' was divided into two items, namely 'I possess the skills that employers are looking for in the labour market' and 'I possess the personal abilities that employers are looking for in the labour market'. This was performed to avoid inaccuracies in the perceptions being measured because of a double-barrelled question. The scale used therefore resulted in 17 items that measured students' perceptions of their university's reputation, their self-belief in terms of their skills and abilities, the status and credibility of their field of study and the status of and opportunities in the external labour market.

\section{Analysis and reporting}

The Statistical Package for the Social Sciences (SPSS Version 26) was used to process the data collected. A confirmatory factor analysis was conducted to validate the factor structure of the self-perceived employability construct and the reliability of the Cronbach's alphas. Descriptive statistics were interpreted and reported by mean and standard deviation. The independent samples $t$-test was used to compare the mean score of two independent groups on the continuous variable self-perceived employability to determine whether they differed significantly (see Frost, 2020). Analysis of variance (ANOVA) was used to compare the mean score of two or more groups on the continuous variable self-perceived employability to determine whether they differed significantly (see Pallant, 2016, p. 109). Post hoc tests were conducted to determine which groups were significantly different from each other (see Pallant, 2016, p. 109). Effect sizes were used to measure the strength of the relationship between two groups; the greater the effect size, the stronger the relationship between two variables and vice versa (see McLeod, 2019). Cohen's $d$-values were used as effect sizes to determine the size of differences between the group means. Cohen (1988) suggested that a $d$-value equal to 0.2 represents a small effect size, a $d$-value equal to 0.5 a medium effect size and a $d$-value equal to 0.8 a large effect size.

\section{Ethical considerations}

The following ethical considerations recommended by Babbie and Mouton (2011, p. 520) and Sarantakos (2013, p. 17) were adhered to during the research: upholding professional integrity, voluntary participation, obtaining informed consent, respecting the privacy of participants, ensuring the anonymity and confidentiality of the research setting and research participants and honesty in reporting on the research data. Approval to conduct the research was obtained from the Arts Research Ethics Committee of the Faculty of Humanities of the university under investigation.

\section{Empirical results Biographical information}

Table 1 presents the biographical information of the respondents.

\begin{tabular}{|c|c|c|c|}
\hline Item & Category & $N$ & $\%$ \\
\hline \multirow[t]{3}{*}{ Gender } & Female & 165 & 68.5 \\
\hline & Male & 75 & 31.1 \\
\hline & Other & 1 & 0.4 \\
\hline \multirow[t]{2}{*}{ Year of study } & First year of registration & 109 & 45.2 \\
\hline & Senior & 132 & 54.8 \\
\hline \multirow[t]{8}{*}{ Faculty of study } & Humanities & 91 & 37.8 \\
\hline & Natural and Agricultural Sciences & 13 & 5.4 \\
\hline & Theology & 4 & 1.7 \\
\hline & Education Sciences & 11 & 4.6 \\
\hline & Economic and Management Sciences & 38 & 15.8 \\
\hline & Law & 8 & 3.3 \\
\hline & Engineering & 16 & 6.6 \\
\hline & Health Sciences & 60 & 24.9 \\
\hline \multirow{5}{*}{$\begin{array}{l}\text { Type of geographical } \\
\text { location in which } \\
\text { respondents mainly } \\
\text { grew up }\end{array}$} & $\begin{array}{l}\text { Big city, for example, Johannesburg/Pretoria/ } \\
\text { Cape Town/Bloemfontein/Port Elizabeth/ } \\
\text { Durban }\end{array}$ & 62 & 25.7 \\
\hline & $\begin{array}{l}\text { Small city, for example, Polokwane/Vereeniging/ } \\
\text { Rustenburg/Mahikeng }\end{array}$ & 85 & 35.3 \\
\hline & $\begin{array}{l}\text { Town, for example, Bethlehem/Wolmaransstad/ } \\
\text { Coligny/Kroonstad/Standerton/Thabazimbi/ } \\
\text { Lichtenburg }\end{array}$ & 62 & 25.7 \\
\hline & $\begin{array}{l}\text { Village/traditional settlement/farm in a rural } \\
\text { area }\end{array}$ & 28 & 11.6 \\
\hline & Other & 4 & 1.7 \\
\hline \multirow{2}{*}{$\begin{array}{l}\text { Previous and current } \\
\text { work experience, for } \\
\text { example, working as a } \\
\text { waiter, cashier, clerk, } \\
\text { voluntary worker, etc. }\end{array}$} & Yes & 130 & 53.9 \\
\hline & No & 111 & 46.1 \\
\hline
\end{tabular}




\section{Self-perceived employability measurement model}

The scale developed by Rothwell et al. (2008) was used to measure undergraduate students' self-perceived employability. Confirmatory factor analysis was conducted to test the structure and relations between the latent variables that underlay the data. Two measurement models were tested: a one-factor model, measuring the employability construct (17 items) and a two-factor model, measuring internal (seven items) and external (10 items) dimensions of employability. Internal employability was measured by Q1, Q2 and Q13 Q17 of the scale and external employability by Q3 - Q12.

All factor loadings, for the one- and the two-factor measurement models, were statistically significant at the 0.05 level. Factor loadings for the one-factor model ranged from 0.321 to 0.713 . For the two-factor model, factor loadings ranged from 0.335 to 0.831 for internal dimensions and 0.346 to 0.661 for external dimensions of employability. The standardised regression coefficients were interpreted as factor loadings; in general, a factor loading of an absolute value of more than 0.3 is regarded as important (Field, 2005, p. 644).

Three goodness-of-model-fit indices were used to determine how well the models fit the data of the sample. They were the chi-square statistic divided by degrees of freedom (CMIN/DF), the comparative fit index (CFI) and the root mean square error of approximation (RMSEA) with its $90 \%$ confidence intervals. Hancock and Mueller (2010) stated that it is good practice to report multiple fit indices, preferably from three broad classes. Table 2 indicates the goodness-of-model-fit indices for the measurement models.

Confirmatory factor analyses showed that the one- and twofactor structures of the employability scale did not fit well to the data of the sample (see Table 2).

Chi-square statistic divided by degrees of freedom is the chisquare fit index divided by degrees of freedom (also called the chi-square to degrees of freedom [DF] ratio). Degrees of freedom ratios between 2 and 3 are indicative of an acceptable fit between the measurement model and the sample data (Carmines \& McIver, 1981, p. 80). According to Mueller (1996) and Paswan (2009, as cited in Shadfar \& Malekmohammadi, 2013, p. 586), in practice, values as high as 3,4 or even 5 still

TABLE 2: Goodness-of-model-fit indices.

\begin{tabular}{lcccc}
\hline Decision rule & \multicolumn{4}{c}{ Model score and outcome } \\
\cline { 2 - 5 } & One-factor & Outcome & Two-factor & Outcome \\
\hline $\begin{array}{l}\text { CMIN/DF } \\
\begin{array}{l}\text { Close to 1; 3-5 } \\
\text { still satisfactory }\end{array}\end{array}$ & 3.836 & Fair fit & 3.127 & Acceptable fit \\
CFI & & & \\
$\geq 0.9$ (good fit) & 0.718 & Not good fit & 0.790 & Not good fit \\
RMSEA & & & & \\
0.01 (excellent) & 0.109 & Not good fit & 0.094 & Not good fit \\
0.05 (good) & {$[0.098 ; 0.119]$} & & $0.083 ; 0.105]$ & \\
0.08 (mediocre) & & & & \\
\hline
\end{tabular}

$\mathrm{CFI}$, comparative fit index; RMSEA, root mean square error of approximation; CMIN/DF, chisquare statistic divided by degrees of freedom. represent an acceptable model fit, depending on the viewpoint of the investigator. Values below 1.0 are considered poor model fit (Shadfar \& Malekmohammadi, 2013, p. 586). Chisquare statistic divided by degrees of freedom values of 3.836 (one-factor) and 3.127 (two-factor) were found for the measurement models, indicating an acceptable fit.

CFI values can range between 0 and 1 (Institute for Digital Research and Education, 2021). Values above 0.9 indicate a good overall fit (Hair, Anderson, Tatham, \& Black, 2010; Mueller, 1996). Comparative fit indices of 0.718 (one-factor) and 0.790 (two-factor) were found for the measurement models, indicating they were not a good fit.

The RMSEA values of $0.01,0.05$ and 0.08 are regarded as indications of excellent, good and mediocre fit, respectively (Institute for Digital Research and Education, 2021). According to Brown and Moore (2012, p. 6), a value of 0 indicates a very good fit. Hu and Bentler (1998, 1999, as cited in Brown \& Moore, 2012, p. 6) recommended a value equal to or smaller than 0.06 as a cut-off value for a good fit. Blunch (2008) suggested that models with RMSEA values of 0.10 and larger should not be accepted. The RMSEA value is commonly reported with its confidence intervals. In a goodfitting model, the lower $90 \%$ confidence level should be close to 0 , whilst the upper level should be below 0.08 (Shadfar \& Malekmohammadi, 2013, p. 588). The one-factor measurement model obtained an RMSEA value of 0.109 with a 90\% confidence interval of 0.098 (low) and 0.119 (high), whilst the two-factor model obtained an RMSEA value of 0.094 with a $90 \%$ confidence interval of 0.083 (low) and 0.105 (high). The results therefore indicated that both the measurement models and the sample data were not a good fit.

As the measurement models analysed indicated 'not a good fit', an exploratory factor analysis was conducted on the 17 Likert-type scale items measuring undergraduate students' self-perceptions of their employability. Principal component analysis and oblimin rotation were employed. The KaiserMeyer-Olkin test yielded a value of 0.856 , suggesting that the sample size was adequate to be used for factor analysis. The $p$-value of Bartlett's test of sphericity was 0.05 , showing that the correlation between items was sufficient for factor analysis (see Field, 2005). Four factors, namely external labour market, academic engagement and performance, self-belief in skills and abilities and university reputation, were extracted that explained 56.94 of the total variance. Kaiser's rule to retain factors that have eigenvalues greater than 1 was applied (Field, 2009, p. 652).

The Cronbach's alpha coefficient for three factors (external labour market: $\alpha=0.779$; self-belief in skills and abilities: $\alpha=0.70$; university reputation: $\alpha=0.75)$ calculated 0.7 and above, showing high reliability and internal consistency. Six statements loaded on external labour market (ranging from 0.396 to 0.816), five on Self-belief in skills and abilities (ranging from 0.240 to 0.852 ) and four on university reputation (ranging 
from 0.587 to 0.764). One item, Q19R7, in the Self-belief in skills and abilities factor, obtained a factor loading of 0.240 ; however, it was decided to retain the item because of its theoretical importance. The academic engagement and performance factor yielded a Cronbach's alpha of 0.539, indicating a low reliability. Only two items loaded on the factor (ranging from -0.338 to -0.600 ). According to Cortina (1993, as cited in Field, 2009, p. 675), the number of items in a scale can influence the value of Cronbach's alpha. On the one hand, a large number of items can possibily result in a higher value of Cronbach's alpha and on the other hand a small number of items could result in a lower value of Cronbach's alpha (Field, 2009, p. 675). The mean inter-item correlation yielded a value of 0.382 , which is sufficient according to Clark and Watson (1995). The following mean scores were obtained for the factors: external labour market: $M=3.58$, academic engagement and performance: $M=4.25$, selfbelief in skills and abilities: $M=3.95$ and university reputation: $M=3.74$.

A confirmatory factor analysis was conducted to test the structure and relations between the latent variables that underlay the data of the four-factor self-perceived employability model; the results are presented in Figure 2.

Table 3 indicates the goodness-of-model-fit indices for this model. Two of the indices showed an acceptable model fit; a CMIN/DF value of 2.406 and an RMSEA value of 0.077 with a $90 \%$ confidence interval of 0.065 (low) and 0.088 (high) were obtained. Furthermore, a relatively acceptable CFI of 0.867 was also found for the model.

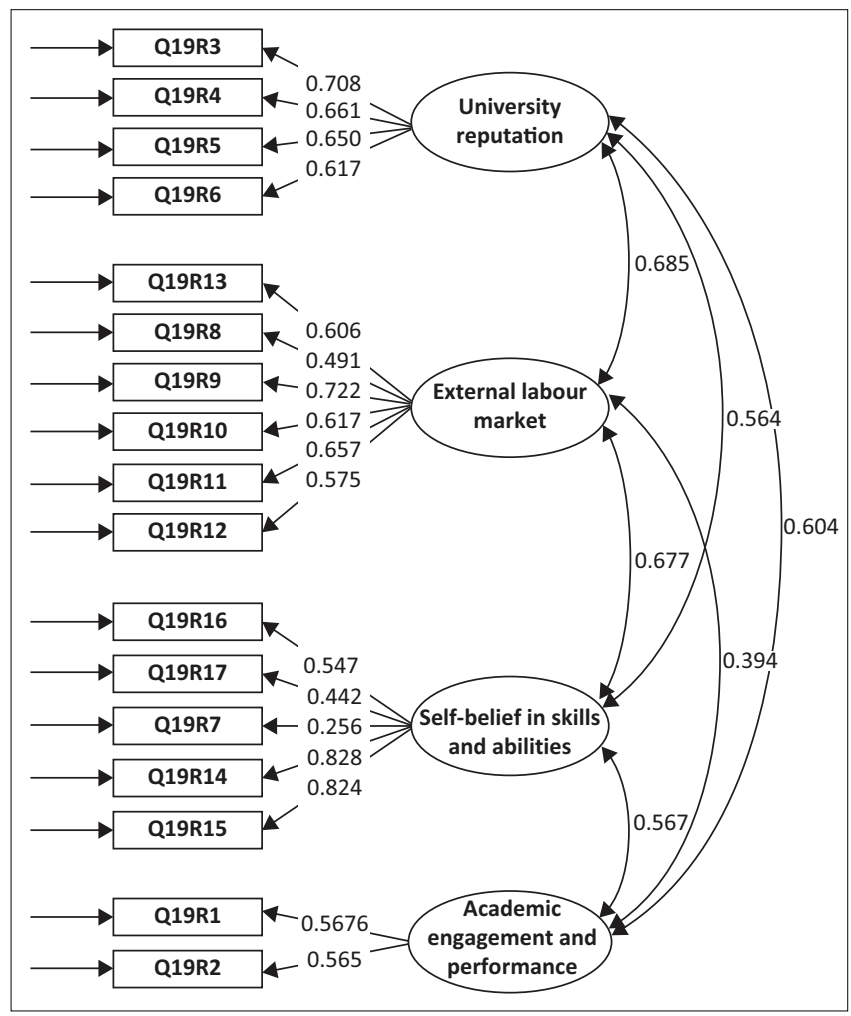

FIGURE 2: Confirmatory factor analysis results for the self-perceived employability model with standardised regression weights and correlations.
TABLE 3: Goodness-of-model-fit indices.

\begin{tabular}{lll}
\hline Decision rule & Four-factor model score & Outcome \\
\hline CMIN/DF & & \\
Close to $1 ; 3-5$ still satisfactory & 2.406 & Acceptable fit \\
CFI & & Relatively acceptable fit \\
$\geq 0.9$ (good fit) & 0.867 & \\
RMSEA & & Acceptable fit \\
0.01 (excellent) & $0.077[0.065 ; 0.088]$ & \\
0.05 (good) & & \\
0.08 (mediocre) & & \\
\hline
\end{tabular}

$\mathrm{CFI}$, comparative fit index; RMSEA, root mean square error of approximation; CMIN/DF, chisquare statistic divided by degrees of freedom.

\section{The association between self-perceived employability and socio-demographic variables}

The results of the t-tests indicated no significant differences between the means of male and female respondents for all the dimensions (factors) of self-perceived employability; all the $p$-values calculated higher than 0.05 . The effect sizes showed a small effect for external labour market $(d=0.22$; male: $M=3.69$; female: $M=3.54)$, academic engagement and performance ( $d=0.21$; male: $M=4.15$; female: $M=4.29$ ) and self-belief in skills and abilities ( $d=0.26$; male: $M=4.06$; female: $M=3.90)$.

The results of the $t$-test showed no significant differences between the means of first-year and senior respondents for all the dimensions (factors) of self-perceived employability; all $p$-values measured higher than 0.05. The effect sizes showed no effect for all the dimensions (factors) of selfperceived employability; all $d$-values were lower than 0.2 .

The results of the $t$-test showed no significant differences between the means of respondents with and without previous and current work experience for all the dimensions (factors) of self-perceived employability; all the $p$-values yielded a value greater than 0.05 . The effect sizes showed a small effect for external labour market ( $d=0.22$; work experience: $M=3.66$; no work experience: $M=3.50)$ and self-belief in skills and abilities $(d=0.21$; work experience: $M=4.01$; no work experience: $M=3.88)$.

The results of the ANOVA showed significant differences between the means of the different faculties for academic engagement and performance ( $p=0.037)$, university reputation ( $p$ $=0.019)$ and external labour market $(p=0.000)$. The post hoc tests showed significant differences between the means of the faculties Humanities and Economic and Management Sciences $(p=0.014 ; d=0.55)$, where the respondents in the Faculty of Economic and Management Sciences $(M=4.39)$ were more positive about their academic engagement and performance than respondents of the Faculty of Humanities $(M=4.11)$. The effect size indicated a medium effect. Furthermore, the post hoc tests indicated that the means of the faculties of Health Sciences and Economic and Management Sciences differed significantly $(p=0.049$; $d=0.57$; the respondents in the Faculty of Economic and Management Sciences $(M=3.99)$ held more positive opinions about the reputation of the university than respondents in the Faculty of Health Sciences $(M=3.63)$. A medium effect was evident from the effect size. In terms of external labour 
market, the post hoc test indicated significant differences between the means of the faculties of Humanities and Natural and Agricultural Sciences/Engineering ( $p=0.012 ; d=0.72$ ), Humanities and Economic and Management Sciences ( $p=0.047 ; d=0.49)$, Natural and Agricultural Sciences/ Engineering and Health Sciences $(p=0.008 ; d=0.76)$ and Economic and Management Sciences and Health Sciences $(p=0.032 ; d=0.60)$. Respondents in the faculties of Natural and Agricultural Sciences/Engineering $(M=3.97)$ and Economic and Management Sciences $(M=3.81)$ were more positive about their employment opportunities in the external labour market than respondents in the faculties of Humanities $(M=3.48)$ and Health Sciences $(M=3.45)$. The effect sizes indicated medium to large effects.

The results of the ANOVA indicated significant differences between the means of the different geographical areas in which the respondents grew up for academic engagement and performance $(p=0.009)$ and for self-belief in skills and abilities $(p=0.011)$. For academic engagement and performance, the post hoc tests (homogeneous subsets) showed that the means of small city $(M=4.13)$ and village/traditional settlement/farm in a rural area $(M=4.14)$ differed significantly from town $(M=4.30 ; d=0.28$ [small city]; $d=0.30$ [rural area]) and big city $(M=4.42 ; d=0.48$ [small city]; $d=0.53$ [rural area]). The effect sizes showed small to medium effects. This indicates that respondents who mainly grew up in towns and big cities held more positive opinions regarding their academic engagement and performance than those who mainly grew up in small cities and rural areas. Similarly, the post hoc tests indicated significant differences between the means of town $(M=4.30)$ and big city $(M=4.42 ; d=0.23)$; the effect size indicated a small effect. Therefore, respondents who mainly grew up in big cities were more positive about their academic engagement and performance than those who mainly grew up in towns. For self-belief in skills and abilities, the post hoc tests showed significant differences between the means of village/traditional settlement/farm in a rural area $(M=3.71)$ and small city $(M=3.88 ; d=0.31)$, big city $(M=4.04 ; d=0.56)$ and town $(M=4.08 ; d=0.67)$. The effect sizes indicated small to medium effects. Therefore, it can be deduced that respondents who mainly grew up in rural areas were less confident about their skills and abilities than those who mainly grew up in towns and small and big cities. In all instances, the $p$-values calculated lower than 0.05 .

\section{Discussion}

This study was conducted to explore the self-perceived employability of undergraduate students at a South African university. The self-perceived employability scale for university students developed by Rothwell et al. (2008) was used.

Confirmatory factor analysis was conducted to test the structure and relations between the latent variables that underlay the data on self-perceived employability. Confirmatory factor analyses showed that both the one- and the two-factor structures (internal and external dimensions) of the self-perceived employability scale did not fit well to the data of the sample. Three goodness-of-model-fit indices (CMIN/DF, CFI and RMSEA) were used; only one index (CMIN/DF) indicated an acceptable fit for both the measurement models and the sample data.

An exploratory factor analysis was therefore conducted on the Likert-type scale items of the self-perceived employability scale. The results showed four factors: external labour market ( $\alpha=0.779)$, academic engagement and performance $(\alpha=0.539)$, self-belief in skills and abilities $(\alpha=0.70)$ and university reputation $(\alpha=0.75)$. The Cronbach's alpha coefficient for three factors showed high reliability and internal consistency. The academic engagement and performance factor yielded a Cronbach's alpha of 0.539 , indicating a relatively low reliability; however, the mean inter-item correlation obtained a value of 0.382 , which is acceptable. Confirmatory factor analyses indicated that the four-factor structure fit well to the data of the sample. Two of the goodness-of-model-fit indices (CMIN/DF \& RMSEA) showed an acceptable model fit, whilst the CFI indicated a relatively acceptable model fit.

The mean scores of all four factors measured above 3.5. The highest mean score was obtained for academic engagement $(M=4.25)$, followed by self-belief in skills and abilities $(M=3.95)$, university reputation $(M=3.74)$ and external labour market $(M=3.58)$. Therefore, the participants scored higher on internal dimensions of self-perceived employability than external dimensions. It can be deduced that although the participants were confident about their internal employability, they were not much confident that they would be able to secure employment in the external labour market. This might be an indication that students were aware of the current economic circumstances, the high unemployment rates and opportunities available in the external labour market in the country.

Regarding the influence of the socio-demographic variables on self-perceived employability, the following results were obtained: The results of the $t$-tests indicated no significant differences between the means of male and female participants, the means of first-year and senior participants and the means of participants with and without previous and current work experience. In all instances, the effect sizes were either small or indicated no effect. Although the studies conducted by Qenani et al. (2014, p. 210), Vargas et al. (2018) and Räty et al. (2020) found significant differences between the means of males and female respondents, this study supported the results of the studies conducted by Rothwell et al. (2009) and Karli (2016), which found no significant differences between the means of male and female participants. This study contradicted the findings of the literature and previous research that indicated an association between age (Jackson \& Wilton, 2017; Karli, 2016; Qenani et al., 2014; Rothwell et al., 2008; Van der Heijden, 2002) and self-perceived employability and previous work experience (Dacre Pool \& Sewell, 2007; Helyer \& Lee; 2014, Jackson \& Wilton, 2017; Knight \& Yorke, 2003; Qenani et al., 2014; Räty et al., 2020) and self-perceived employability. 
However, the results of the ANOVA test indicated significant differences between the means of the different fields of study for academic engagement and performance, university reputation and external labour market. Respondents studying in the Faculty of Economic and Management Sciences were more positive about their academic engagement and performance than respondents studying in the Faculty of Humanities. Respondents studying in the Faculty of Economic and Management Sciences were more positive about the reputation of the university than respondents studying in the Faculty of Health Sciences. Furthermore, respondents studying in the faculties of Natural and Agricultural Sciences/Engineering and Economic and Management Sciences were more positive about their employment opportunities in the external labour market than respondents in the faculties of Humanities and Health Sciences. The results of the study confirmed the results obtained by Vargas et al. (2018) and Räty et al. (2020), who also found that students studying in the field of humanities displayed lower levels of selfperceived employability in comparison with students studying in other fields of study. In addition, the study found that students studying in engineering and economic and management sciences were more optimistic about their employment prospects in the external labour market than students studying in other fields of study.

The ANOVA test showed significant differences between the means of the different geographical areas in which students mainly grew up for academic engagement and performance and for self-belief in skills and abilities. Respondents who mainly grew up in big cities were more positive about their academic engagement and performance than those who mainly grew up in towns. Furthermore, respondents who mainly grew up in rural areas were less confident about their skills and abilities than those who mainly grew up in towns and small and big cities. Watson (2017, p. 277) and Harry et al. (2018, p. 5) indicated that one's background (class, family and educational and socioeconomic background) may influence one's aspirations and employment prospects.

\section{Limitations}

The sample of the study only included undergraduate students of one site of delivery of the higher education institution (university) in South Africa; therefore, undergraduate students of the two other sites of delivery were excluded. The results of the study can therefore not be generalised to all students of the institution.

\section{Recommendations}

In order for the study to apply to a larger context, the study could be extended to include a larger population and sample, including other higher education institutions in South Africa. This will allow for comparisons between the samples and might provide valuable information for the higher education sector.

\section{Conclusion}

The primary purpose of this study was to explore the selfperceived employability of undergraduate students at a South African university. The results indicated that the students were relatively confident about their internal employability, but they were less confident about their opportunities in the external labour market. Although the current economic circumstances and the structural nature of unemployment in South Africa are not ideal to easily realise opportunities in the external labour market, it is of utmost importance that young people be aware of the skills and accompanied experience required in the labour market. Continuous investment in those skills will enhance students' employability and will consequently enable them to secure employment and to become successful citizens and employees.

\section{Acknowledgements}

The author is grateful for the 2020 honours students in Sociology at the higher education institution under investigation who collected the data and for the statistical consultation services of the higher education institution under investigation who processed the collected data.

\section{Competing interests}

The author declares that she has no financial or personal relationships that may have inappropriately influenced her in writing this article.

\section{Author's contributions}

D.B. conducted the literature review, interpreted the empirical results and wrote up the article.

\section{Funding information}

This research received no specific grant from any funding agency in the public, commercial or not-for-profit sectors.

\section{Data availability}

The data that support the findings of this study are available on request from the author (D.B.).

\section{Disclaimer}

The views and opinion expressed in this article are those of the author and do not necessarily reflect the official policy or position of any affiliated agency of the author.

\section{References}

Babbie, E., \& Mouton, J. (2011). The practice of social research. Oxford: Oxford University Press.

Blunch, N.J. (2008). Introduction to structural equation modelling using SPSS and AMOS. Los Angeles, CA: Sage.

Brown, T.A., \& Moore, M.T. (2012). Confirmatory factor analysis. Retrieved from https://www.researchgate.net/profile/Michael-Moore-75/publication/ 251573889_Hoyle_CFA_Chapter_-_Final/links/Odeec51f14d2070566000000/ Hoyle-CFA-Chapter-Final.pdf 
Carmines, E.G., \& Mclver, J.P. (1981). Analyzing models with unobserved variables. In G.W. Bohrnstedt \& E.F. Borgatta (Eds.), Social measurement: Current issues (pp. 65-115). Los Angeles, CA: Sage.

Clark, L.A., \& Watson, D. (1995). Constructing validity: Basic issues in objective scale development. Psychological Assessment, 7(3), 309-319. https://doi. org/10.1037/1040-3590.7.3.309

Cloete, A. (2015). Youth unemployment in South Africa: A theological reflection through the lens of human dignity. Missionalia, 43(3), 513-525. https://doi. org/10.7832/43-3-133

Cohen, J. (1988). Statistical power analysis for the behavioral sciences (2nd ed.) Mahwah, NJ: Erlbaum.

Creswell, J.W., \& Creswell, J.D. (2018). Research design: Qualitative, quantitative, and mixed methods approaches (5th ed.). Los Angeles, CA: Sage.

Dacre Pool, L., \& Sewell, P. (2007). The key to employability: Developing a practical model of graduate employability. Education and Training, 49(4), 277-289. https:// doi.org/10.1108/00400910710754435

De Vos, A., De Hauw, S., \& Van der Heijden, B.I.J.M. (2011). Competency development and career success: The mediating role of employability. Journal of Vocational Behavior, 79(2), 438-447. https://doi.org/10.1016/j.jvb.2011.05.010

Edgell, S., \& Granter, E. (2019). The sociology of work: Continuity and change in paid and unpaid work. Los Angeles, CA: Sage.

Field, A. (2005). Discovering statistics using SPSS (2nd ed.). Los Angeles, CA: Sage.

Field, A. (2009). Discovering statistics using SPSS (3rd ed.). Los Angeles, CA: Sage.

Frost, J. (2020). How t-tests work: T-values, $t$-distributions and probabilities. Statistics by Jim. Retrieved from https://statisticsbyjim.com/hypothesis-testing/t-tests-tvalues-t-distributions-probabilities/

Fugate, M., \& Kinicki, A.J. (2008). A dispositional approach to employability: Development of a measure and test of implications for employee reactions to organizational change. Journal of Occupational and Organizational Psychology, 81(3), 503-527. https://doi.org/10.1348/096317907X241579

Groot, W., \& Van den Brink, H.M. (2000). Education, training and employability. Applied Economics Journal, 32, 573-581. https://doi.org/10.1080/000368400322471

Hair, J.R., Anderson, R.E., Tatham, R.L., \& Black, W.C. (2010). Multivariate data analysis (7th ed.). Hoboken, NJ: Prentice-Hall.

Hancock, G.R., \& Mueller, R.O. (2010). The reviewer's guide to quantitative methods in the social sciences. London: Routledge.

Harry, T., Chinyamurindi, W.T., \& Mjoli, T. (2018). Perceptions of factors that affect employability amongst a sample of final-year students at a rural South African university. SA Journal of Industrial Psychology/SA Tydskrif vir Bedryfsielkunde, 44, a1510. https://doi.org/10.4102/sajip.v44i0.1510

Helyer, R., \& Lee, D. (2014). The role of work experience in the future employability of higher education graduates. Higher Education Quarterly, 68(3), 348-372. https:// doi.org/10.1111/hequ.12055

Hillage, J., \& Pollard, E. (1998). Employability: Developing a framework for policy analysis (Research Report No. RR85). Retrieved from https://d1watxts1xzle7. cloudfront.net/43539201/Employability_Developing_a framework_for20160309-24658-1ix1nw2-with-cover-page-v2.pdf? Expires $=1635282732 \&$ Signature $=$ d0gaunWsrlTd3n2HP5qLFpghvqrzQND612e-o0z GO xOS7GtRDXHxCFzK3pMBnlu2geWtCnqtwUavb5a9-mBaKBmnfPKx-xLTOOa9iW cvga8bLC3U6g5IYpU0I9SB7uHM3/w rKRWMNNV4vzJQ709GGQ18Ud5UbACt5vf wf-uc5s $\sim$ kvPx8h4yCrULte4z8Ccbp3ytPKCoKUoqeDUAbG1805sElxbTvLNbJwJMO0 wf-uc5s kvPx8h4yCrULte4z8Ccbp3ytPKCOKUoqeDUAbG1805sElxbTvLNbJwJMOO ePEwLDH9 DJ5RhiOQKrvtrEi9UpQ0Kk7MGO3X7SujYtlps7fJ7vXS25ycdS6FMocWJ
ycwANH3E90jcuKTXIIv12YIg9kBXQfRK7gFh rPPWAmuw_\&Key-PairId=APKAJLOHF5GGSLRBV4ZA

Hooley, T. (2017). Climbing the employability mountain. Retrieved from https://derby openrepository.com/bitstream/handle/10545/621626/climbing+the+employabil ity+mountain.pdf?sequence $=1$

Institute for Digital Research and Education. (2021). A practical introduction to factor analysis: Confirmatory factor analysis. Retrieved from https://stats.idre.ucla.edu/ spss/seminars/introduction-to-factor-analysis/a-practical-introduction-to-factoranalysis-confirmatory-factor-analysis/

Jackson, D., \& Wilton, N. (2017). Perceived employability among undergraduates and the importance of career self-management, work experience and individual characteristics. Higher Education Research \& Development, 36(4), 747-762. https://doi.org/10.1080/07294360.2016.1229270

Juhdi, N., Pa'Wan, F., Othman, N.A., \& Moksin, H. (2010). Factors influencing internal and external employability of employees. Business and Economics Journal, 11 $1-10$.

Karli, U. (2016). Adaptation and validation of self-perceived employability scale: An analysis of sports department students and graduates. Educational Research and Reviews, 11(8), 848-859.

Knight, P.T., \& Yorke, M. (2003). Employability and good learning in higher education. Teaching in Higher Education, 8(1), 3-16. https://doi.org/10.1080/ 1356251032000052294

Law, B., \& Watts, A.G. (2003). The DOTS analysis - Original version. The Career Learning Network. Retrieved from https://www.hihohiho.com/memory/cafdots.pdf

McLeod, S. (2019). What does effect size tell you? Simply Psychology. Retrieved from https://www.simplypsychology.org/effect-size.htm

Moolman, H. (2017). A conceptual competence-based framework for enhancing the employability of graduates. The Independent Journal of Teaching and Learning, 12(2), 26-43.
Mueller, R.O. (1996). Basic principles of structural equation modelling: An introduction to LISREL and EQS. Berlin: Springer.

Nogales, R., Córdova, P., \& Urquidi, M. (2020). The impact of university reputation on employment opportunities: Experimental evidence from Bolivia. The Economic and Labour Relations Review, 31(4), 524-542. https://doi.org/10.1177/ 1035304620962265

Oluwajodu, F., Blaauw, D., Greyling, L., \& Kleynhans, E.P.J. (2015). Graduate unemployment in South Africa: Perspectives from the banking sector. SA Journa of Human Resource Management/SA Tydskrif vir Menslikehulpbronbestuur, 13(1), a656. https://doi.org/10.4102/sajhrm.v13i1.656

Pallant, J. (2016). SPSS survival manual: A step by step guide to data analysis using IBM SPSS (6th ed.). New York, NY: McGraw-Hill.

Paterson, R. (2017). Because sometimes your failures can also teach you certain skills: Lecturer and student perceptions of employability skills at a transnational university. Qualitative Research in Education, 6(3), 241-275. https://doi. org/10.17583/qre.2017.2583

Qenani, E., MacDougall, N., \& Sexton, C. (2014). An empirical study of self-perceived employability: Improving the prospects for student employment success in an uncertain environment. Active Learning in Higher Education, 15(3), 199-213. https://doi.org/10.1177/1469787414544875

Quiring, S., Boys, S., \& Harris, E. (2017). The role of self-efficacy in employability: Implications for pedagogical change. Thurgood Marshall Law Review, 43(1), 533-550.

Räty, H., Hytti, U., Kasanen, K., Komulainen, K., Siivonen, P., \& Kozlinska, I. (2020). Perceived employability and ability self among Finnish university students. European Journal of Psychology of Education, 35, 975-993. https://doi. org/10.1007/s10212-019-00451-7

Reuters. (2021). South Africa's unemployment rate jumps to new record high. Retrieved from https://www.reuters.com/article/us-safrica-economyunemployment-idUSKBN2ANOS1

Rothwell, A., \& Arnold, J. (2007). Self-perceived employability: Development and validation of a scale. Personnel Review, 36(1), 23-41. https://doi. validation of a scale. Perso
org/10.1108/00483480710716704

Rothwell, A., Herbert, I., \& Rothwell, F. (2008). Self-perceived employability: Construction and initial validation of a scale for university students. Journal of Vocational Behavior, 73(1), 1-12. https://doi.org/10.1016/j.jvb.2007.12.001

Rothwell, A., Jewell, S., \& Hardie, M. (2009). Self-perceived employability: Investigating the responses of post-graduate students. Journal of Vocational Behavior, 75(2), 152-161. https://doi.org/10.1016/j.jvb.2009.05.002

Rothwell, A.T. (2015). Employability. In P.J. Hartung, M.L. Savickas, \& W.B. Walsh (Eds.), APA handbook of career intervention (pp. 337-350). Worcester, MA: American Psychological Association.

Sarantakos, S. (2013). Social research (4th ed.). London: Palgrave Macmillan.

Shadfar, S., \& Malekmohammadi, I. (2013). Application of structural equation modeling (SEM) in restructuring state intervention strategies toward paddy production development. International Journal of Academic Research in Business and Social Sciences, 3(12), 576-618. https://doi.org/10.6007/IJARBSS/v3-i12/472

Statistics South Africa. (2020). Vulnerability of youth in the South African labour market. Retrieved from http://www.statssa.gov.za/?p=13379

Statistics South Africa. (2021a). More people participate in the South African labour market in the 4th quarter of 2020. Retrieved from http://www.statssa.gov. $z a / ? p=14031$

Statistics South Africa. (2021b). Quarterly labour force survey (QLFS) Q2:2021. Retrieved from http://www.statssa.gov.za/publications/P0211/Presentation $\% 20$ QLFS\%20Q2_2021.pdf

Stojanováa, H., \& Blaškováa, V. (2014). The role of graduates' field of study and its impact on the transition to working life. Procedia Economics and Finance, 12, 636-643. https://doi.org/10.1016/S2212-5671(14)00388-8

Thijssen, J.G.L., Van der Heijden, B.I.J.M., \& Rocco, T.S. (2008). Toward the employability-link model: Current employment transition to future employment perspectives. Human Resource Development Review, 7, 165-183. https://doi. org/10.1177/1534484308314955

Van Broekhuizen, H. (2016). Graduate unemployment and higher education institutions in South Africa (Stellenbosch Economic Working Paper No. 08/16). Retrieved from https://resep.sun.ac.za/wp-content/uploads/2018/07/wp-08-2016.pdf

Van der Heijden, B. (2002). Prerequisites to guarantee life-long employability Personnel Review, 31(1), 44-61. https://doi.org/10.1108/00483480210412418

Vargas, R., Sanchez-Queija, M.I., Rothwell, A., \& Parra, A. (2018). Self-perceived employability in Spain. Education and Training, 60(3), 226-237. https://doi. employability in Spain. Educatic
org/10.1108/ET-03-2017-0037

Wakefield, H.I., Yu, D., \& Swanepoel, C. (2020). Revisiting transitory and chronic unemployment in South Africa. Development Southern Africa. Retrieved from https://www.tandfonline.com/doi/pdf/10.1080/0376835X.2020.1799761?casa https://www.tandfonline.com/doi/pdf/10.1080/0376835X.2020.1799761?casatoken=L9ulzfClbgAAAAAA:IUgwq3fE75mmy5 BJX
3UXXTmFKqbt3gs_6aHqpetaLaAqZ-qncWCn6jLUudnU

Watson, T. (2017). Sociology, work and organisation (7th ed.). London: Routledge.

Yu, D., \& Swanepoel, C. (2021). Granular understanding of joblessness in South Africa can help pinpoint policies. Polity. Retrieved from https://www.polity.org.za/ article/granular-understanding-of-joblessness-in-south-africa-can-help-pinpointpolicies-2021-03-10

Zikmund, W.G., Babin, B.J., Carr, J.C., \& Griffin, M. (2010). Business research methods (8th ed.). Boston, MA: South-Western Cengage Learning. 